\title{
Strategic Management Practices and Barriers in Rural SMEs
}

\author{
Article by Vishvanath K.P.V. Doerga \\ Management, Texila American University, Guyana \\ E-mail: vishnudoerga@actioncoach.com
}

\begin{abstract}
Small and Medium Enterprises (SMEs) make up the majority of business entities in the region and contribute significantly to revenue generation and employment. For SMEs to be profitable and to grow into larger corporate entities, a significant amount of management capacity is required.

As a SME owner, private sector leader and management student, the author has recognised a significant gap which exists between SMEs and the knowledge required by owners to deploy an effective company strategy to maximise potential of a business. The purpose of this research study is to examine the need for this gap to be addressed, the level of strategic thinking among owners which exists -if any; and the barriers to its inclusion by SMEs in Guyana.

By investigating and studying twenty three (23) organisations in a rural community, reference was made to both quantitative and qualitative data from respondents in the context of management knowledge literature of SMEs. Host country and knowledge provider perspectives were also considered.

The results of the research confirmed the limited to average level of strategic thinking which currently exists in the majority of SMEs. By addressing the identified knowledge gap all the parties involved including the SMEs, the host country and the knowledge providers are likely to benefit significantly in terms of increased revenues, profits and employment.
\end{abstract}

\section{Introduction}

SME owners who also function as managers stand to significantly benefit from the acquisition of management knowledge. Without strategic thinking, management and execution, many businesses fail and disappear from the industry, others stagnate but survive, some are swallowed by larger businesses, and only rarely do they go on to greatness' (AIB study notes, 2011).

This research study focuses on the degree of deployment of a company strategy by rural SMEs which is among the most critical factors in developing a business. "A company's strategy consists of the competitive moves and business approaches that managers are employing to grow the business, attract and please customers, compete successfully, conduct operations, and achieve targeted levels of organizational performance (Thompson, Strickland \& Gamble 2010, p. 6).

While heading the Upper Corentyne Chamber of Commerce and Industry (UCCCI) from 2010 to 2012, focusing on enhancing management knowledge and working with a very diverse membership, it was evident that a significant proportion of SME management did not possess the requisite strategic management skills to fully develop the potential of their respective businesses. There seemed to be a gap between the availability of management knowledge and the lack of its deployment by SMEs. There is a great deal of literature available on the strategic management field and efforts are made by agencies to ensure that SMEs have access to funding and third party assistance packages. There is a lack of research on integrating management knowledge into local SMEs particularly as it relates to ascertaining the reasons for the hesitance displayed by SMEs to adopt recognized strategic management practices. By researching this critical gap, it is anticipated that more clarity and possible solutions are forthcoming. 
DOI: $10.21522 /$ TIJMG.2015.03.02.Art009

ISSN: $2520-310 \mathrm{X}$

This report comprises of five sections following this introduction which includes: an orientation of the research, data collection and analysis, key findings, key implications and conclusion.

\section{Orientation}

The identification and continued evolution of a company's strategy is cited in literature as a key success factor. Management authors have stressed the importance of managing strategically. To do so, however, requires significant knowledge in order to gain the benefits sought after. Strategic management is a field that deals with the major intended and emergent initiatives taken by general managers on behalf of owners, involving utilization of resources, to enhance the performance of firms in their external environments (Nag, Hambrick \& Chen 2007, p. 935).

\section{Definitions}

Nag, Hambrick and Chen separate the roles of owners and managers for good reason. According to the Merriam-Webster's Dictionary and Thesaurus (2007) an owner is defined as, 'one that owns: and one that has legal or rightful title whether the possessor or not'. As such, an owner is also described as a proprietor. A manager is defined as 'one who handles or directs with a degree of skill: by judicious use of means to accomplish an end'. These definitions outline the requirement of skill, which the manager would possess, in order to achieve company objectives.

\section{SME classification}

The Caricom Development Fund defines Small and Medium Enterprises as: "a small Enterprise with less than 25 employees, less than US\$50,000 invested in equipment, or less than US\$25,000 in annual sales and Medium-sized Enterprise as an Enterprise with 25-50 employees, with US\$50,000US $\$ 200,000$ invested in equipment, or US\$25,000-US\$250,000 in annual sales" (Caricom Development Fund 2011).

\section{SME importance}

SMEs are a major source of employment. They account for some 50 per cent of employment in the Caribbean Region, and contribute about 40 per cent to the Region's GDP. In agriculture, SMEs account for over 70 per cent of the main export crops and an even higher proportion of domestic food crops (Caricom Development Fund 2011). The sector is therefore central to the survival and success of CARICOM of which Guyana is a member.

Due to the relatively smaller size of SMEs as compared to corporations, SME owners generally perform the functions of manager. As noted, the critical difference between owner and manager is the level of skill required to efficiently and effectively achieve objectives.

Jay Goltz (2012) of the New York Times noted the most important reasons for the failure of small businesses. They are as follows; a lack of standards and controls, not having the right people, complacency, poor accounting and dysfunctional management. He postulates further that many of the reasons for failure can be addressed by small businesses if they were to employ recognized management practices.

\section{Case study}

The mandate of the Upper Corentyne Chamber of Commerce and Industry (UCCCI) is to make representation on behalf of its members on issues affecting the private sector in the region.

The target of this research will be the UCCI's SME membership. The area represented is classified as non-urban (rural) since the population and business density is much lower than that of the Capital city of Georgetown. Businesses represented include a wide range of companies in the trading, mining, forestry, agriculture, financial and services sectors. 
This organization was chosen due to the level of access available to the researcher within the relatively short research time frame, secondly because of apparent SME management deficiencies and finally since there seemed to be a genuine lack of research into the barriers that exist to accessing management knowledge in the minds of SME owners. Since the literature highlights the lack of management capacity as a major reason for lack of SME development, this research may be useful to local SMEs as well as SMEs operating under similar conditions.

Any improvement in SME management will have a significant cumulative effect not only on the individual SMEs, but also the national economy with SMEs becoming more efficient and profitable. SME expansion into corporate entities with larger employment and sales turnover will accelerate the country's development rate. Knowledge providers would also benefit from better understanding and addressing of SME needs.

\section{Data collection and analysis}

This study utilises the case study research strategy focused on the SME membership of the UCCCI. It employs an empirical investigation into the management practices pursued by twenty three of the thirty nine identified SMEs.

The organisation comprises of 63 members (table 1) with 39 being classified as SMEs based on the Caricom Development Fund guidelines. The remaining members are categorised as corporations and employed professionals, and were therefore excluded from the research. Due to the relatively manageable size of the SME population within this organization, it was decided to collect primary data from the entire SME membership. This would allow for a more accurate analysis of the organization's members and would avoid generalizations having to be made if a smaller sample were to be selected.

\section{Questionnaire and interview}

The research utilises a structured administered questionnaire and interview (appendix 2) session with each participant and seeks to identify the existence or non-existence of strategic management practices. It uses carefully crafted questions to identify barriers to the implementation and possible solutions. It was decided to use this method since the respondents were mainly, busy sole SME proprietors with limited time available and scheduling two separate sessions may have resulted in lower participation.

Personally administering the questionnaire also allowed for further explanations to be given when necessary and for a smooth transition into the interview segments of the document. Due to this limited time availability it was decided to seek both quantitative and qualitative data during the session. This would allow for an analysis that would produce findings based on empirical quantitative data while at the same time providing much needed insight, via the qualitative data gained from opinions expressed in the interviews segments.

\section{Research focus}

The research document consisted of 23 questions (appendix 2) and took about one-half to one hour per participant depending on the depth the participants were prepared to go into during the qualitative segments. The questionnaire attempts to obtain the following data:

1. To what level is strategic management deployed in SMEs?

2. Is strategic management seen as a critical business success factor?

3. Do owners/managers (UN) consciously apply strategic management practices?

4. Do owners/managers see the necessity for strategic management practices?

5. What are the barriers to implementing strategic management practices?

6. What are the barriers to obtaining the tools of strategic management? 
DOI: $10.21522 /$ TIJMG.2015.03.02.Art009

ISSN: $2520-310 \mathrm{X}$

7. What steps need to be and are taken to implement strategic management?

The following are used as indicators of the existence/non-existence of strategic management:

1. Strategic vision and mission

2. Company values

3. Strategic and financial objectives

4. Short, medium and long term strategic plans

5. Executing, monitoring and revision of plans

6. Competitive advantage strategy

7. Porter's five forces analysis

8. Company profitability

9. Long term growth

10. Employee and customer satisfaction

\section{Strategic thinking}

Questions 1 to 7 and 9 attempt to classify the respondents into different groupings in order to investigate if any relationship exists between particular groupings and opinions expressed. Questions 14 to 21 attempt to identify strategic thinking and include sections for other views to be expressed. Questions 8, 10 to 13,22 and 23 are questions seeking to gain the respondents views of management issues.

The arrangement of the questions allows for progressively focussing the respondent's attention on the area of management thinking, starting off with general questions and narrowing down to the data sought. The areas that focus on uncovering management thinking focuses on identifying the company's vision, values, objectives, focus and planning. These are all areas critical to determining how much thought was given to strategic thinking.

\section{Consent}

The interview sessions follows ethical procedures for this type of research as outlined in the AIB Guidelines. The organization provided consent for access to its membership and all interviewees signed the research consent forms.

\section{Data collection}

The data was collected from the $13^{\text {th }}$ to the $26^{\text {th }}$ of August 2012, completing about two sessions per day. Notice of the research was provided to the 39 SME owners via email and follow up phone calls. A total of 23 sessions were completed within the scheduled two week window resulting in a $59 \%$ active response rate. At a $95 \%$ level of statistical validity, the sample size of 23 respondents out of a population of 39 , resulted in a $11.13 \%$ margin of error.

The remaining $41 \%$ of SME owners were unable to participate due to varying reasons mainly, unavailability and timing issues. However, some fear by potential participants to be included in an academic study that may have brought to light personal or management inadequacies was evident. Assurances were given about the confidential nature of the study and this resulted in a greater participation rate.

Half of the $41 \%$ of unavailable participants did not respond to the initial email and contact by telephone on at least two occasions proved futile. This information was noted in keeping with guidelines for such interactions (Saunders, Lewis \& Thornhill 2007).

All interviews were conducted at the SMEs places of business at times agreed on by the respondents. Approximately half of the 23 respondents had a formal office space, the remainder used a section of their business space to have the meeting. Very rarely did the interviews go uninterrupted, due to the fact that these SME owners were the sole source for the bulk of information required by 
their employees. All respondents seemed to answer the questions to the best of their abilities and some asked for further elaboration of the questions. It was apparent that many of the respondents had not given much thought to the importance of management to their businesses. At the completion of the session respondents were thanked for their time and asked if they had any questions. When questions were raised, appropriate answers were given.

\section{Data analysis}

The data gathered was then entered into an Excel workbook for processing. Using the coding guidelines outlined in the Research Methods for Business Students (Saunders, Lewis \& Thornhill 2007), a matrix was created to determine the value of the data. To gauge strategic thinking, a scale of zero to five was used in the excel sheet to rate how closely views expressed resembled recognized management knowledge.

With zero representing no knowledge, one representing very limited knowledge, two representing some knowledge, three representing average knowledge, four representing better than average knowledge and five representing in-depth knowledge. The soundness of the received responses was evaluated based on the reviewed management literature.

\section{Quantitative analysis}

A detailed Excel analysis is found in table 1 and following are some of the quantitative highlights from the analysis. The 23 respondents were confirmed to be SMEs with $65 \%$ listed as small businesses and $35 \%$ as medium sized businesses. Although gender was not included in the questionnaire, it was noted that there was only one female participant out of the twenty three reflecting strong male leadership dominance in the local SME sector. This unforeseen factor may have some influence on the level of strategic thinking being applied but due to the fact that there was only one female participant it is difficult to make any such generalisations based on the garnered data.

The respondents were equally dispersed into the different age categories indicating differing experience levels.

The majority of respondents (74\%) personally established their businesses and $69 \%$ had been in business for over 10 years. This served the research well since there were no businesses in the startup phase (less than one year), when the focus would have been more on carving a foothold then the wider management focus.

The majority (96\%) of respondents had some formal schooling with $27 \%$ having university training and only $4 \%$ with formal management training. Although businesses generally rated their performance as successful, the level of the strategic thinking indicators ranged from very limited to average. The weakest area of strategic thinking was observed to be the setting of objectives for the business. Just two participants had some semblance of strategic or financial objectives. The majority of respondents had not given much thought to setting future business goals and seemed content with letting their business 'float with the tide'.

The majority of respondents had a short term business focus mainly thinking about the next few weeks to months. In examining the education level a pattern was noted with the more educated participants having a higher level of strategic thinking. These more educated participants were able to indicate their company's vision, objectives and values. However, the more educated participants also seemed to have time management issues.

The majority agreed that improved management capacity was very important to the future survival of their businesses believing that it would improve their businesses. Increased competition is the main factor (57\%) that would force participants to seek an improved level of management capacity with many opting to access improved capacity by researching ideas online, hiring qualified management personnel and undertaking management training. The greatest barriers to accessing 
DOI: $10.21522 /$ TIJMG.2015.03.02.Art009

ISSN: $2520-310 \mathrm{X}$

improved management capacity was cited as 'not having enough time' (57\%) followed by 'no access to capacity building sources' $(17 \%)$.

\section{Qualitative analysis}

While the quantitative analysis sorted the data in a manner that provided oversight, the qualitative analysis brought to light many of the underlying factors that restricted the improvement of management capacity.

When discussing competitive market behaviour most participants indicated that they were aware of competitive moves, however about a quarter responded that they do not pay attention to competitors business since they find that to be an unethical practice. They preferred to use the 'shopkeepers attitude' which basically entails buying a product for $\mathrm{x}$ and selling for $\mathrm{x}+$ profit without much consideration to external pressures on the business.

SME owners perceived employee attitudes to the participant's management style to be in the somewhat motivated range indicating much room for improvement in that respect. Customer attitudes were perceived to be in the motivated range possibly reflecting the close relationship most SME owners share with their customers.

Very little was being done to improve management capacity with participants having the perception that staff inadequacy was the reason their management capacity remained stagnant. Staff meetings and on the job employee training were cited as measures to improve management capacity by the respondents that did have some improvement measures in place.

Fear of unfamiliar management practices and the need for simpler management courses were also highlighted as issues preventing improvements. Several participants indicated their reluctance to apply new strategies due to the fear of failure and subsequent loss of authority over employees. As one participant noted: 'My staff will lose respect for me, if I try new things and it doesn't work!'

The lone participant with formal management training remarked: 'Having management skills definitely gives you a competitive edge', while a less qualified participant remarked: 'When I retire, I will close the businesses. Table 3 provides more highlights of respondents' general views of management. Government inefficiencies, corruption and brain drain were other factors that hampered business growth as revealed during the interview section of the questionnaire.

In general it was noted that all respondents wanted to improve their businesses but seemed unclear of how the improving of their management capacity would assist them in achieving that goal. This confirms that a gap does exist between these firms and the wealth of management knowledge.

\section{Key findings}

The study finds a relatively low level of strategic thinking within the participating SMEs.

A positive correlation exists between the level of education and the degree of deployment of strategic management. The higher the education level, the greater the degree of deployment. Most of the participants believe their businesses to be successful. However, they agree that accessing an improved level of management capacity is very important to the future survival of their businesses. They also agree that the implementation of recognized strategic management practices is likely to make make an immediate improvement in their businesses. They see increased competition as one variable forcing them to seek an improved level of management capacity.

Many participants show a preference for hiring qualified staff, searching for ideas online and undertaking management training as ways to increase the level of strategic management. Many also state that 'a lack of time' and 'a lack of capacity building sources' are the greatest obstacles to accessing management tools. 
Using management tools such as project management which focuses on scheduling and time management, delegation, training and strategy formulation, could allow SME owners to spend time on strategies to achieve long term growth and profitability. The non-awareness of the benefits that strategic management practices is one of the most important conclusions of this research. It is as if SME owners know the practices exist, know that larger companies use them to their benefit, but still do not make the connection to their own business.

\section{Key implications}

This study provides an understanding the dynamics behind the management behaviour of participating SME owners in the Upper Corentyne district of Guyana. The implications are diverse and are addressed in terms of effects on the main stakeholders in the following order; the SMEs, the host country and knowledge providers.

\section{SME implications}

The analysis of this research study confirms a SME management inadequacy. A volume of management material and knowledge providers exist. Furthermore, the steps taken by the national government also seem to be geared to SME growth. The issue then has to be mainly internal to the SMEs. The realisation of the importance of proper management practices, to a large extent has to come from SME owners. This realisation can be externally strengthened by governments and knowledge providers by these institutions creating more awareness about the need for and benefits of applying recognized management practices.

It seems that the basis of not having the time to access greater management capacity coupled with perceived success and low current levels of competition creates a comfort zone for SMEs in which a relaxed attitude is cultivated. It is, therefore, possible that future competitors with higher levels of management capacity could easily out-compete current SMEs. This effect may become more pronounced as competition forces urban SME owners to expand into rural areas.

It should then be of utmost importance for local SMEs to analyse their current position, identify their long term goals and the level of management capacity required to achieve these goals. As a number of SMEs have evolved from the micro enterprise stage, where the owner was the sole decision maker and in many cases the sole employee, these businesses are now at a stage where without improved management capacity it will be difficult to graduate into larger enterprises or corporations.

In theory, it is believed that strategic thinking using the multiplicity of management tools can lead a company to achieve a sustainable competitive advantage (Thompson, Strickland \& Gamble 2010). Using the many management tools can also allow owners to 'gain' more of their own time. One such tool would be delegation, whereby supervisory staffs are trained to perform many of the repetitive, non-critical tasks that are presently keeping SME owners occupied. This will also reduce the stress levels caused by being engaged in the constant occupational grind. Time freed up can be used to focus on long term planning and discovering deficiencies in the current modus operandi. SMEs need to be made aware of these benefits. Significant results of SMEs actively improving their management capacity could be increased revenue, profitability and employment.

\section{Host country implications}

First, at a local level and progressively felt at the host country level (Guyana), better management practices would lead to increased revenues and profits. This effect would mean higher levels of taxation to be collected by the government of Guyana in furtherance of developing infrastructure and improving the standard of living of its citizens. Increased employment would also benefit tax collection and more so would serve to alleviate poverty and welfare dependence. With a higher 
DOI: $10.21522 /$ TIJMG.2015.03.02.Art009

ISSN: $2520-310 \mathrm{X}$

standard of living and more spending power among the masses, SME growth could theoretically become a self-perpetuating economic driver.

Based on this research, it would be prudent for government and private sector agencies to actively promote the enhancement of management capacity within SMEs.

\section{Knowledge provider implications}

It was strange to conclude that many SMEs believed that there was no access to capacity building sources, especially since the author, a SME owner himself, sought out these sources in order to further develop his skills and business. The low SME owner enrolment into one 'practical' MBA course lends strength to the mindset SME owners currently have.

Another, more practical view was expressed by one participant who felt that shorter, simpler management courses were needed, that catered more closely to the needs of SME owners and staff, who, as the study indicates, posses mainly primary or secondary level education. This identified barrier would need to be addressed by the providers of management capacity and knowledge.

It may be a case of marketing to this particular segment of SME owners who require the skills to further develop their businesses. This segment would be more interested in learning how to apply management concepts than on passing exams and receiving credentials since they already have their own businesses and would probably not use the credentials to gain employment elsewhere.

It may therefore mean that the marketing has to be more focused on the benefits that improving management capacity will have on the SME as against gaining credentials. It is noted that many marketers, including knowledge providers, view their services as bundles of attributes, but consumers tend to think about services in terms of their consequences instead (Belch \& Belch 2009).

This is a critical gap that needs to be addressed by knowledge providers, since they possess the knowledge product which the SME market, arguably, requires the most and as this research suggests, the SME owners do not know how to access. It is stated that the SME market arguably requires this knowledge the most, since SMEs provide about $40 \%$ of the regions GDP and $50 \%$ of its employment (Caricom Development Fund 2011).

Therefore any improvements in the management capacity of these SMEs can have tremendous economic effects. If knowledge providers were to focus on this segment and identify success stories along the way, significantly more SMEs may want to access their services making for a profitable segment. It must also be noted that knowledge providers need to seek ways to address the fear of academic failure that seemingly exists within SME owners. Creating and marketing simple management courses that focus on the practical and realistic management applications may be one feasible direction.

\section{Conclusion}

It is noted that improving the level of strategic management knowledge is important to the survival of SMEs by improving the way business is done. Although this realization exists among SMEs, firm steps are not being taken to address this issue. Lack of time and capacity building sources are cited as the main barriers. Ironically, many of the issues faced by SMEs could have been resolved by applying better management practices.

It remains to be seen if the recommended approach of creating the necessary awareness and possibly the creation of new courses would close the identified gap but the benefits to be derived for all involved, including the SMEs, the host country and the knowledge providers are numerous. For the SMEs and knowledge providers these include increased revenues, profitability and employment. For the host country, increased tax collection and reduced unemployment are among the main benefits.

This research study has highlighted SME barriers and the gap that currently exists between those entities that possess and those that require the knowledge. A conscious, concerted effort by the three 
main involved parties of SMEs, host country and knowledge providers, will be required to address this gap in order for the benefits to be derived.

Not addressing this gap will maintain the status quo with inefficiencies holding on to the space that truly belongs to growth and prosperity.

\section{References}

[1]. Belch, GE, \& Belch, MA 2009, Advertising and Promotion, An integrated Marketing Communications Perspective, 8th edition, McGraw-Hill, Boston, USA.

[2]. Caricom Development Fund, 2011, Maintaining agile businesses; Identifying and Using Opportunities for Success, A Manual for CARICOM Small and Medium-Sized Enterprises, Pear Tree Press, Jamaica.

[3]. Computer World 2012, Internationally Recognized Diploma in Microcomputer Studies, Kaieteur News, 30 September 2012 edition, National Media \& Publishing Company Ltd, Georgetown, Guyana.

[4]. Goltz, J 2011, Top 10 reasons small businesses fail, The New York Times, viewed 9 July 2012, http://boss.blogs.nytimes.com/2011/01/05/top-10-reasons-small-businesses-fail/

[5]. Goltz, J 2012, Why small businesses fail to grow, The New York Times, viewed 9 July 2012,

[6]. http://boss.blogs.nytimes.com/2012/04/10/why-small-businesses-fail-to-grow/

[7]. IPED 2012, Financial Management for MSME's, Guyana Chronicle, 30 September 2012 edition, Guyana National Newspapers Limited, Georgetown, Guyana.

[8]. Merriam-Webster Incorporated 2007, Merriam-Webster's Dictionary and Thesaurus, first edition, USA.

[9]. Nag, R, Hambrick, DC, Chen, MJ, 2007, What is strategic management, really? Inductive derivation of a consensus definition of the field, Strategic Management Journal. Volume 28, Issue 9, pages 935-955, September 2007.

[10]. National Competitiveness Strategy Unit 2011, National Competitiveness Summit 2011 Report, Government of Guyana, Georgetown, Guyana, April 2012.

[11]. Nations University 2012, Earn an MBA in 12 Months, received from Brian O'Toole via email on 8 October 2012.

[12]. Payne, PA 1994, A study of small and medium enterprises in Guyana, Program on innovations systems management, Latin America \& the Caribbean regional office, Uruguay.

[13]. Saunders, M, Lewis, P \& Thornhill, A 2009, Research Methods for Business Students, 4th Edition, FT Prentice Hall, Harlow, England.

[14]. Thompson, AA, Strickland, AJ, and Gamble, JE 2010, Crafting and Executing Strategy,17th Edition, McGraw-Hill Irwin, New York.

[15]. University of Guyana 2012, Evening Classes, Stabroek News, 30 September 2012 edition, Guyana Publications Inc, Georgetown, Guyana.

\section{Appendices}

Table 3 Management comments 
DOI: 10.21522/TIJMG.2015.03.02.Art009

ISSN: 2520-310X

Table 1. Respondents analysis sheet

\begin{tabular}{|c|c|c|c|c|c|c|c|c|c|c|c|c|c|c|c|c|c|c|c|c|c|c|}
\hline Business Name & Business type & $\begin{array}{c}\text { Sor M } \\
\text { Business }\end{array}$ & $\begin{array}{c}\text { Years in } \\
\text { Operation }\end{array}$ & Age & $\begin{array}{c}\text { Business } \\
\text { origin }\end{array}$ & Education & $\begin{array}{c}\text { strategic } \\
\text { management' } \\
\text { meaning }\end{array}$ & \begin{tabular}{|c|} 
Business \\
Performance
\end{tabular} & $\begin{array}{l}\text { Company } \\
\text { Purpose }\end{array}$ & Values & Objectives & Pressures & $\begin{array}{c}\text { Strategy } \\
\text { focus }\end{array}$ & \begin{tabular}{|c|} 
Employee \\
attitude
\end{tabular} & $\begin{array}{l}\text { Customer } \\
\text { Attitude }\end{array}$ & $\begin{array}{c}\text { Implementation } \\
\text { Effect }\end{array}$ & $\begin{array}{l}\text { Improve } \\
\text { Capacity }\end{array}$ & $\begin{array}{l}\text { Access } \\
\text { source }\end{array}$ & Barrier & $\begin{array}{c}\text { Management } \\
\text { Importance }\end{array}$ & Measures & \\
\hline 1 Country Side Hardware & Hardware & 2 & 4 & 3 & 3 & 5 & 1 & 2 & 2 & 4 & 0 & 2 & 2 & 4 & 3 & 2 & 4 & 4 & 7 & 2 & 1 & 0 \\
\hline 2S. Paul Roopnarine Eng. Est. & Workshop & 1 & 4 & 5 & 1 & 4 & 1 & 4 & 3 & 3 & 4 & 2 & 3 & 6 & 3 & 2 & 1 & 1] & 7 & 1 & 3 & 1 \\
\hline 3 Vishnu Super Store & General Store & 1 & 4 & 5 & 1 & 3 & 2 & 4 & 2 & 2 & 1 & 3 & 3 & 3 & 2 & 1 & 1 & 5 & 7 & 2 & 2 & 1 \\
\hline 4 D. Subnauth Filling Station & Gas Station & 1 & 4 & 6 & 1 & 2 & 1 & 4 & 1 & 3 & 0 & 2 & 6 & 2 & 3 & 2 & 5 & 5 & 6 & 2 & 1 & 3 \\
\hline 5 La Grille Restaurant & Hospitality & 1 & 2 & 3 & 1 & 5 & 2 & 3 & 4 & 4 & 0 & 3 & 4 & 3 & 1 & 1 & 4 & 4 & 7 & 1 & 0 & 0 \\
\hline 6B. Khemraj Auto Spares & Auto Spares & 1 & 2 & 2 & 1 & 3 & 2 & 4 & 3 & 2 & 1 & 3 & 4 & 2 & 2 & 2 & 1 & 1 & 7 & 1 & 2 & 1 \\
\hline \multicolumn{2}{|c|}{ 7 JP Ghamandi Hardware Centr Hardware } & 1 & 4 & 6 & 1 & 2 & 1 & 4 & 2 & 3 & 1 & 3 & 1 & 2 & 2 & 2 & 4 & 4) & 2 & 1 & 2 & 1 \\
\hline 8 Pawaroo General Store & General Store & 2 & 4 & 4 & 3 & 5 & 3 & 4 & 3 & 3 & 2 & 4 & 6 & 2 & 2 & 1 & 1 & 1 & 6 & 1 & 2 & 2 \\
\hline 9 K. Dhanai \& Associates & Consultant & 1 & 4 & 5 & 1 & 3 & 3 & 4 & 4 & 3 & 0 & 1 & 3 & 2 & 2 & 2 & 1 & 3 & 7 & 2 & 0 & 2 \\
\hline 10 Joe's Avon Distribution & Distribution & 1 & 2 & 6 & 1 & 5 & 4 & 4 & 4 & 4 & 2 & 3 & 4 & 2 & 2 & 1 & 1 & 1 & 4 & 1 & 3 & 3 \\
\hline \multicolumn{2}{|c|}{11 Bissoon's Business Enterprise Import } & 1 & 4 & 4 & 1 & 3 & 2 & 5 & 2 & 3 & 1 & 3 & 3 & 3 & 2 & 1 & 5 & 5 & 7 & 1 & 4 & 2 \\
\hline 12 R. Singh \& Sons & Sawmilling & 2 & 4 & 3 & 3 & 5 & 2 & 4 & 2 & 3 & 3 & 2 & 1 & 1 & 2 & 2 & 1 & 1 & 8 & 1 & 2 & 1 \\
\hline \multicolumn{2}{|c|}{13 K. Nizamudeem Business Ent Import } & 2 & 2 & 4 & 1 & 2 & 1 & 5 & 3 & 3 & 3 & 1 & 2 & 6 & 2 & 3 & 5 & 5 & 6 & 2 & 1 & 2 \\
\hline 14 Swiss Establishment & Distribution & 1 & 4 & 6 & 1 & 1 & 1 & 4 & 2 & 2 & 1 & 2 & 2 & 2 & 3 & 2 & 1 & 1] & 7 & 1 & 0 & 0 \\
\hline 15 Corriverton Medical Centre & Medical & 1 & 4 & 5 & 1 & 5 & 3 & 4 & 3 & 2 & 1 & 2 & 3 & 2 & 2 & 2 & 4 & 5 & 1 & 2 & 3 & 1 \\
\hline 16 Zaladin Industrial co & Mining & 2 & 4 & 4 & 3 & 2 & 2 & 4 & 3 & 3 & 2 & 3 & 1 & 2 & 1 & 2 & 1 & 1 & 7 & 1 & 3 & 3 \\
\hline 17 Dudnath's Hardware & Hardware & 1 & 4 & 6 & 1 & 2 & 3 & 2 & 3 & 3 & 2 & 4 & 2 & 2 & 3 & 1 & 3 & 8 & 8 & 1 & 0 & 2 \\
\hline 18 Jainarine Fishing Ent & Fishing & 1 & 3 & 4 & 3 & 3 & 3 & 4 & 3 & 3 & 3 & 3 & 3 & 2 & 2 & 1 & 1 & 1 & 7 & 1 & 2 & 2 \\
\hline 19 R\&F Supermarket & Food & 1 & 4 & 4 & 1 & 3 & 2 & 4 & 3 & 3 & 0 & 1 & 1 & 2 & 1 & 3 & 1 & 1 & 7 & 1 & 2 & 1 \\
\hline 20 RLK Ent & Construction & 2 & 4 & 5 & 1 & 3 & 3 & 4 & 4 & 2 & 3 & 2 & 3 & 6 & 2 & 2 & 1 & 1] & 6 & 1 & 2 & 1 \\
\hline 21 MM Latif & Import & 2 & 4 & 5 & 1 & 2 & 2 & 4 & 2 & 1 & 0 & 3 & 3 & 2 & 4 & 3 & 5 & 5 & 7 & 3 & 0 & 1 \\
\hline 22 Tejram General Store & Retail & 1 & 3 & 5 & 1 & 3 & 2 & 5 & 2 & 3 & 1 & 3 & 3 & 2 & 2 & 2 & 3 & 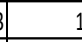 & 1 & 2 & 3 & 1 \\
\hline 23 Shell Corriverton & Services & 2 & 2 & 3 & 4 & 6 & 1 & 4 & 4 & 4 & 4 & 4 & 3 & 2 & 2 & 1 & 1 & 1 & 7 & 1 & 4 & 4 \\
\hline & & Small $=15$ & 3.47826087 & 4.47826087 & 71.565217 & 73.34782609 & 2.043478261 & $\begin{array}{lll}13.913043478\end{array}$ & 2.7826087 & 2.869565 & 1.52173913 & 2.56521739 & 2.869565 & 2.6956522 & 2.173913043 & 1.782608696 & $6 \mid C=57 \%$ & MT $=18 \%$ & $P C=9 \%$ & 1.391304348 & $\begin{array}{ll}3 & 1.826087\end{array}$ & 1.521739 \\
\hline & & $65 \%$ & $<1=0 \%$ & $<20=0 \%$ & $P=74 \%$ & $N F=4 \%$ & & & & & & & & & & & $L F=0 \%$ & $H C=9 \%$ & $U R=4 \%$ & & & \\
\hline & & Medium $=$ & $1-5=22 \%$ & $20-29=5 \%$ & $A=0 \%$ & $P S=27 \%$ & & & & & & & & & & & $\mathrm{ES}=9 \%$ & $\mathrm{OL}=22 \%$ & $\mathrm{NN}=0 \%$ & & & \\
\hline & & & $5-10=9 \%$ & $30-39=17 \%$ & $6 \mid=22 \%$ & $S S=35 \%$ & & & & & & & & & & & MS $=17 \%$ & $\mathrm{NN}=4 \%$ & $\mathrm{NB}=4 \%$ & & & \\
\hline & & & $>10=69 \%$ & $40-49=26 \%$ & $\mathrm{~F}=4 \%$ & TVT $=4 \%$ & & & & & & & & & & & Oth $=17 \%$ & $H Q=22 \%$ & $\mathrm{NC}=0 \%$ & & & \\
\hline & & & & $50-59=30 \%$ & & $U T=27 \%$ & & & & & & & & & & & & $\mathrm{RB}=13 \%$ & $C B=17 \%$ & & & \\
\hline & & & & $60+=22 \%$ & & $\mathrm{MT}=4 \%$ & & & & & & & & & & & & $D F=9 \%$ & $\mathrm{NT}=57 \%$ & & & \\
\hline & & & & & & & & & & & & & & & & & & 0 th $=4 \%$ & Oth $=9 \%$ & & & \\
\hline
\end{tabular}

Source: Developed for this research using Microsoft Excel 


\section{Management comments}

My management skills can't suffice if workers are not adequately ready to accept.

Staff needs to be more dedicated

Outside management in not needed in case of business decline.

By participating in this interview I have suddenly realized the importance and scope of $n$

It is all about daily improvement

Government inefficiencies

Need institutions to do short courses in this area

Management is a dynamic situation needing continuous improvements.

Corruption leads to mismanagement

We have the best management in our sector.

Mismanagement can cripple business

Never give any thought to management

Would consider increased management capacity is expansion plans are followed

Outward migration causing staff shortages leading to high training cost

Can't take a vacation because business may fall apart

Overseas thinking would not work here

Without respect you can not move forward

When I retire, I will close the business

Previous experience would be beneficial

Having Management skills definitely gives you a competitive edge

Source: Developed for this research 